\title{
BMJ Open Is density of neighbourhood restaurants associated with BMI in rural Chinese adults? A longitudinal study from the China Health and Nutrition Survey
}

\author{
Wenwen Du, ${ }^{1}$ Chang Su, ${ }^{1}$ Huijun Wang, ${ }^{1}$ Zhihong Wang, ${ }^{1}$ Youfa Wang, ${ }^{2}$ \\ Bing Zhang ${ }^{1}$
}

To cite: Du W, Su C, Wang $\mathrm{H}$, et al. Is density of neighbourhood restaurants associated with $\mathrm{BMI}$ in rural Chinese adults? A

longitudinal study from the China Health and Nutrition Survey. BMJ Open 2014;4: e004528. doi:10.1136/ bmjopen-2013-004528

- Prepublication history for this paper is available online. To view these files please visit the journal online (http://dx.doi.org/10.1136/ bmjopen-2013-004528)

Received 22 November 2013 Revised 29 March 2014 Accepted 2 April 2014

CrossMark

\footnotetext{
${ }^{1}$ National Institute for Nutrition and food Safety, Chinese Center for Disease Control and Prevention, Beijing, China

${ }^{2}$ Department of Social and Preventive Medicine, University at Buffalo, State University of New York, Buffalo, New York, USA

Correspondence to Dr Bing Zhang; zzhangb327@aliyun.com
}

\begin{abstract}
Objectives: The neighbourhood availability of restaurants has been linked to the weight status. However, little is known regarding the relation between access to restaurant and obesity among the Chinese population. This study aims to explore the relationship between neighbourhood restaurant density and body mass index (BMI) in rural China.

Design: A longitudinal study using data from the China Health and Nutrition Survey (CHNS) was conducted. Participants aged 18 and older from the 2004, 2006, 2009 and 2011 CHNS were recruited Separate sexstratified random intercept-slope growth models of repeated BMI observations were estimated in the study. Setting: The data were derived from rural communities in nine provinces in China.
\end{abstract}

Participants: There were 11835 male and 12561 female person-years assessed in this study.

Outcomes: The primary outcome of this study was weight status. It is defined as a BMI value, a continuous variable which is calculated by dividing weight $(\mathrm{kg})$ by the square of height $\left(\mathrm{m}^{2}\right)$.

Results: The study indicated that among men an increase of one indoor restaurant in the neighbourhood was associated with a $0.01 \mathrm{~kg} / \mathrm{m}^{2}$ increase in BMI, and an increase of one fixed outdoor food stall was associated with a $0.01 \mathrm{~kg} / \mathrm{m}^{2}$ decrease in BMI, whereas among women, an increase of one indoor restaurant in the neighbourhood was associated with a $0.005 \mathrm{~kg} / \mathrm{m}^{2}$ increase in BMI, and an increase of one fast-food restaurant and one fixed outdoor food stall was associated with a 0.02 and $0.004 \mathrm{~kg} / \mathrm{m}^{2}$ decline in BMI, respectively.

Conclusions: The density of neighbourhood restaurants was found to be significantly related to BMI in rural China. The results indicated that providing healthy food choices and developing related public health policies are necessary to tackle obesity among rural Chinese adults.

\section{INTRODUCTION}

China has been experiencing dramatic economic and social changes in the past

\section{Strengths and limitations of this study}

- This study added evidence on the neighbourhood availability of restaurants and its relation with weight status, especially for the low-income population in China, using large-scale longitudinal data.

- The major limitation of this study is the inability to define a clear association between restaurant density and body index mass. Restaurants nearby or located outside the neighbourhood were not included in this study.

- Other unobserved factors, such as work intensity, home location and frequency of eating out, were also not included in this paper. In addition, the study did not incorporate the distance to a restaurant, which may influence the results.

decades, which has affected their lifestyles and thus resulted in an obesity epidemic. ${ }^{1}$ By 2030 , the respective number of overweight and obese adults is projected to be 669 million and 141 million individuals, respectively, in China. ${ }^{2}$ Although the prevalence rates of overweight almost doubled between 1991 and 2004 in China, it became less concentrated in more urbanised areas, and urbanicity-related inequalities have decreased over time. ${ }^{3}$ For women living in communities with a low initial urbanicity score, however, a higher level of change in urbanicity is associated with significantly higher odds of overweight/obesity during the follow-up time. ${ }^{4}$

The Chinese diet is shifting from traditional foods towards high-energy density, high-fat and low-fibre diets. ${ }^{5}{ }^{6}$ The lowincome population, which is defined as the population having limited social and economic resources and is linked with disparities in access to healthy foods, has the highest decrease in cereal food intake. Owing to rapid urbanisation and socioeconomic changes, eating away from home is increasing 
rapidly in China. Between 2000 and 2008, the share of food expenditure on eating away from home rose from $14.70 \%$ to $20.61 \% .^{7}$ With the increasing prevalence of obesity and modern eating behaviours, especially in lowincome populations, the role of the neighbourhood food environment has been paid more attention. A number of international studies have pointed out that the nutritional quality of foods consumed away from home is considerably poorer than that of foods eaten or prepared at home, because they contain higher fat and energy intake, lower fibre and micronutrients intake. ${ }^{8-13}$ Owing to the excessive portion size of energy-dense foods served in restaurants, eating away from home may lead to a positive energy balance and thereby contribute to the current obesity pandemic in western countries. ${ }^{14-18}$ Different effects of restaurant food and fast-food intake on body mass index (BMI) were also found. ${ }^{19}$ Eating out frequently, specifically at buffets, cafeterias and fast-food restaurants, was associated with higher rates of obesity. ${ }^{20}$ Studies highlighted that fast-food restaurant density was associated with a higher individual-level BMI and risk of being obese ${ }^{21}{ }^{22}$; however, a higher density of a full-service restaurant was associated with lower weight status. ${ }^{22}$

Eating away from home has taken a large part in the Chinese diet, due to rapid urbanisation and income growth. In China, social and economic characteristics have underlined the significant urban-rural disparities. Most studies have focused on the urban context, while little is known about the rural Chinese population. The decrease of agricultural labour has caused eating out behaviour to be prominent in rural areas. When compared with their urban counterparts, rural residents have limited choices of restaurants. Low education and low income level are also the potential factors underlying the unequal food environment effects. Thus, studies assessing urban individuals cannot be applied in the rural context. In this multilevel study, we examined the association of the density of neighbourhood restaurants, which is defined as the number of fast-food restaurants, indoor restaurants and fixed outdoor food stalls in the neighbourhood, with BMI of adults in rural China. Furthermore, we also investigated the effects of the neighbourhood food environment on weight status for the low-income Chinese population.

\section{METHODS}

\section{Study population}

Data in this paper were derived from the China Health and Nutrition Survey (CHNS), which covers nine provinces of China started in 1989, and followed by 1991, 1993, 1997, 2000, 2004, 2006, 2009 and 2011. The survey was originally designed to examine the influence of social and economic transformation among Chinese society on their health and nutritional status. There were in total 4400 households consisting of 19000 individuals. Detailed information about the CHNS can be found in the following link: http://www.cpc.unc.edu/ projects/china.

The participants included in this study were rural Chinese adults aged 18 and older from the 2004, 2006, 2009 and 2011 CHNS. There were 11835 male and 12561 female person-years included in this study, while pregnant women, disabled persons and individuals with missing values were excluded.

\section{Dependent variables}

Height and weight were measured by qualified field staff using standard techniques and equipment. BMI was calculated by dividing weight $(\mathrm{kg})$ by square of height $\left(\mathrm{m}^{2}\right)$. We used BMI as a continuous variable to examine its association with neighbourhood restaurant density.

\section{Individual-level variables}

The following individual-level variables were included in this study: age (years), gender $(0=$ female; $1=$ male), marital status ( $1=$ currently married; $0=$ others), highest level of education ( $0=$ junior high school or lower; 1=high school; $2=$ college or higher), per capital household income (RMB/person×year), current smoking $(0=$ no; $1=y e s)$, drinking $(0=$ no; $1=y e s)$, motorcycle ownership $(0=$ no; $1=$ yes $)$, car ownership $(0=$ no; $1=y e s)$ and moderate/heavy physical activity in working hours $(0=$ no; $1=y e s)$. The individual-level variables were timevarying variables, except gender.

\section{Neighbourhood-level variables}

We utilised a multidimensional index developed specifically for the CHNS to capture the urbanisation level in Chinese communities. ${ }^{4}$ The index comprised 12 components, in which each component was assigned 10 points and summed up to a maximum value of 120 points. The index covers population density, transportation infrastructure, housing infrastructure, sanitation, health infrastructure, availability of social services, communication infrastructure, education level, economic activity, variance in education and income level, presence of traditional food markets and presence of western food establishments. A higher index score represented a higher degree of urbanisation. Traditional food markets and western food establishments were excluded from the study in order to avoid confounding effects.

There were three types of restaurant in the neighbourhood that were included in this study: fast-food restaurants, indoor restaurants and fixed outdoor food stalls. Using the Community Questionnaires, the community leaders were asked about the number of restaurants currently operating in the neighbourhood. Fast-food restaurants were defined as restaurants or fast-food restaurant chains that served western-style food products, such as McDonald's, Kentucky Fried Chicken and Pizza Hut. Indoor restaurants referred to those which are operated indoors, or inside an enclosed structure that has a roof and well-covered walls, and in which cooking and eating are performed indoors. Food stalls referred to those 
which are operated outdoors at a fixed place; it may have a roof, but no walls, and cooking and eating are performed outdoors.

\section{Statistical analyses}

Statistical analyses were performed using SAS V.9.2 (SAS Institute, Cary, North Carolina, USA). Descriptive statistics on individual demographic variables and BMI in each survey wave for men and women were analysed separately to illustrate the adjusted trends in the sample.

To examine the different changes in rates over time, we employed difference tests between any two consecutive waves on urbanicity index, density of fast-food restaurants, indoor restaurants and fixed outdoor food stalls in the neighbourhood.

We estimated sex-stratified random intercept-slope growth models of repeated BMI observations. Survey years were coded as 0, 1, 2 and 3 for 2004, 2006, 2009 and 2011 , respectively. In model 1 , only survey year was included to examine the time effects on BMI growth. The individual-level variables were then added into the equation to estimate model 2, with age (grand-mean centred), marital status (ref=currently not married), education level (ref=junior high school and lower), per capita household income (ref=low tertiles), drinking (ref=no), smoking ( $r e f=n o)$, moderate/heavy physical activity (ref=no), motorcycle ownership ( $\mathrm{ref}=\mathrm{no}$ ) and car ownership (ref=no). For model 3, neighbourhood-level predictors were added on model 2. These include the numbers of fast-food restaurants, indoor restaurants and fixed outdoor food stalls in the neighbourhood, and urbanicity index tertiles.

\section{RESULTS}

Descriptive demographics for the sample population are presented in table 1. A total of 11835 male and 12561 female person-years over all the survey waves were analysed, with the average age of men increasing from 46.93 to 51.30 and that of women from 46.86 to 51.07 . Almost $85 \%$ of respondents were currently married, of whom around $80 \%$ of men and $87 \%$ of women attained junior high school or lower level of education. The average per capita household income in 2011 was almost two times higher compared with that in 2004. The prevalence rates of drinking and smoking were higher among men; roughly $61 \%$ drank alcohol and $57 \%$ smoked cigarettes. In terms of moderate/heavy physical activity, almost $59 \%$ of men and $44 \%$ of women participated in moderate/ heavy physical activity during working hours.

As for BMI trends, there was increasing prevalence of men with BMI $\geq 25$ from $19.27 \%$ in 2004 to $26.91 \%$ in 2011 , and of BMI $\geq 30$ from $1.98 \%$ to $4.31 \%$. The prevalence of women with BMI $\geq 25$ also increased from $23.62 \%$ in 2004 to $27.74 \%$ in 2011 , and of BMI $\geq 30$ from $3.97 \%$ to $5.66 \%$. Figure 1 plotted the percentage of BMI distribution, which indicated that men and women gained weight during the survey time.

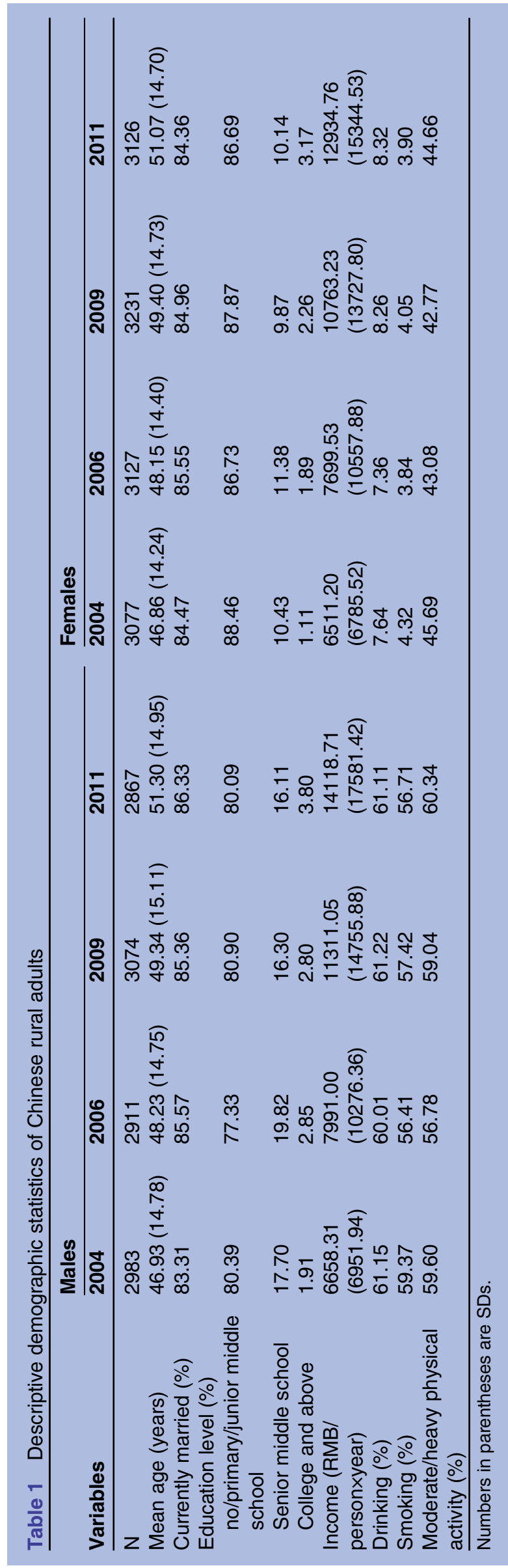


Figure 1 Body mass index (BMI) distribution trend among Chinese rural adults (20042011).

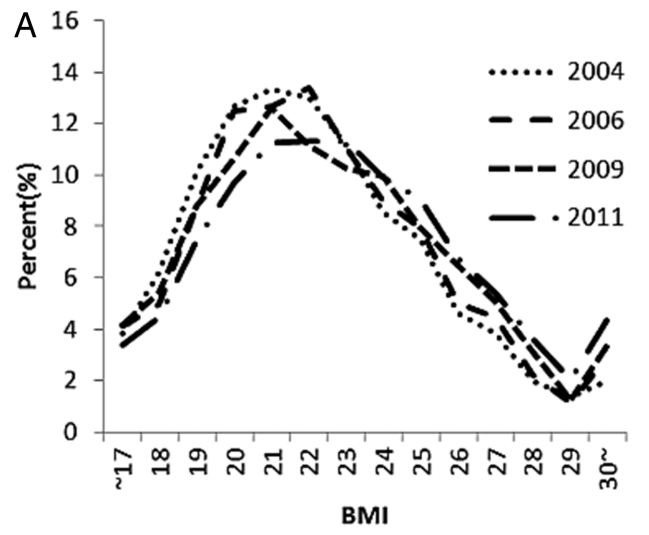

Regarding neighbourhood-level characteristics, table 2 showed the increase of urbanicity index among rural communities, with the highest interval growth of 3.66 from 2006 to 2009, while the other two change intervals accounted for about 1.9 increases. The density of fast-food restaurants was found to be relatively low in rural China, while indoor restaurants and fixed outdoor food stalls were the most popular types of restaurants. The survey indicated that the different types of restaurants in the neighbourhood had no significant difference.

We estimated three-level random intercept-slope linear growth models of BMI for men (table 3) and women (table 4) separately. First, we only included survey year in the model, and found a positive association with BMI for men and women (model 1). Then in model 2, we added time-varied individual characteristic variables. Currently married, higher education level, higher household income, drinking and owning a motorcycle were positively associated with the increase of BMI among men, while smoking and having moderate/heavy physical activity were negatively associated with BMI. For women, higher age and currently married were positive predictors for BMI; however, higher education level and having moderate/heavy physical activity were significantly associated with lower BMI. Finally, we estimated model 3 to examine the community effects. For men, neighbourhood variables were significantly related to the BMI, except the density of fast-food restaurants. The study indicated that higher urbanicity tertiles were associated with the increase of BMI, that is, an increase of one indoor restaurant in the neighbourhood was associated with a $0.01 \mathrm{~kg} / \mathrm{m}^{2}$ increase in BMI, while an increase of one fixed outdoor food stall in the neighbourhood was associated with a $0.01 \mathrm{~kg} / \mathrm{m}^{2}$ decrease in BMI among rural men. For women, all neighbourhood variables were significantly related to BMI. The results indicated that urbanisation was positively associated with $\mathrm{BMI}$, that is, an increase of one indoor restaurant in the neighbourhood was associated with a $0.005 \mathrm{~kg} / \mathrm{m}^{2}$ increase in BMI, while an increase of one fast-food restaurant or fixed outdoor food stall was associated with a 0.02 or $0.004 \mathrm{~kg} / \mathrm{m}^{2}$ decline in BMI among rural women.

\section{DISCUSSION}

Over the past decades, upward trends of overweight/ obesity were noted in men and women, all age groups, rural/urban areas and all level of education groups, with greater increase in men, individuals aged 18-64 years and rural residents among the Chinese population. ${ }^{23} 24$ Rural women had a greater prevalence rate of overweight, general obesity and abdominal obesity than their urban counterparts in 2009, while rural men had an almost similar trend with urban men in weight status variables. The downward trends of urban-rural difference in health and nutritional status were also reported in other studies. ${ }^{325}$ A study reported that, among lower gross domestic product (GDP) countries, increased per capita GDP is associated with increases in the absolute annual change in prevalence of overweight/obesity, mainly in rural areas. ${ }^{26}$ Another study explained that the decreased intake of cereals and increased consumption

Table 2 Changes in the neighbourhood food environment in rural China: 2004-2011

\begin{tabular}{lcccc}
\hline Variables & $\mathbf{2 0 0 4}$ & $\mathbf{2 0 0 6}$ & $\mathbf{2 0 0 9}$ & $\mathbf{2 0 1 1}$ \\
\hline Urbanicity index & $52.92(16.66)^{*}$ & $54.82(17.25)^{*}$ & $58.48(60.39) \dagger$ & $60.39(15.93) \dagger$ \\
Number of fast-food restaurants in the neighbourhood & $0.28(1.54)$ & $0.49(2.61)$ & $0.1(0.51)$ & $0.13(0.89)$ \\
Number of indoor restaurants in the neighbourhood & $6.53(13.42)$ & $7.65(14.45)$ & $5.61(8.94)$ & $6.08(10.49)$ \\
Number of fixed outdoor food stalls in the neighbourhood & $6.28(12.71)$ & $6.83(12.58)$ & $4.17(9.71)$ & $3.97(8.60)$ \\
\hline *Indicated that the differences in urbanicity index values in 2004, 2006, 2009 and 2011 were insignificant, while the last two waves have \\
higher index scores than the first two waves $(p<0.05)$. Numbers of three kinds of restaurant in the neighbourhood found no significant change \\
between four survey waves $(p>0.05)$.
\end{tabular}


Table 3 Estimates from the three-level linear growth models examining body mass index among rural men ( $\mathrm{N}=11835)$ 2004-2011

\begin{tabular}{|c|c|c|c|}
\hline & Model 1 & Model 2 & Model 3 \\
\hline Intercept & $22.54(0.05)^{*}$ & $21.85(0.10)^{*}$ & $21.68(0.10)^{*}$ \\
\hline Year (ref=2004) & $0.28(0.02)^{*}$ & $0.26(0.02)^{*}$ & $0.26(0.02)^{\star}$ \\
\hline \multicolumn{4}{|l|}{ Individual level } \\
\hline Age (grand-mean centred) & & $0.00(0.00)$ & $0.00(0.00)$ \\
\hline Currently married $(\mathrm{ref}=\mathrm{no})$ & & $0.75(0.08)^{\star}$ & $0.74(0.08)^{*}$ \\
\hline Education level (ref=no/primary/junior) & & $0.24(0.06)^{\star}$ & $0.22(0.06)^{*}$ \\
\hline Per capita household income (ref=low) & & $0.11(0.03)^{\star}$ & $0.10(0.03)^{*}$ \\
\hline Drinking $(r e f=n o)$ & & $0.12(0.04)^{*}$ & $0.12(0.04)^{*}$ \\
\hline Smoking (ref=no) & & $-0.15(0.04)^{*}$ & $-0.15(0.04)^{*}$ \\
\hline Moderate/heavy physical activity (ref=no) & & $-0.16(0.04)^{*}$ & $-0.13(0.04)^{*}$ \\
\hline Motorcycle ownership $(\mathrm{ref}=\mathrm{no})$ & & $0.10(0.04)^{*}$ & $0.10(0.04)^{*}$ \\
\hline Car ownership (ref=no) & & $0.03(0.07)$ & $0.02(0.07)$ \\
\hline \multicolumn{4}{|l|}{ Neighbourhood level } \\
\hline Number of fast-food restaurants in the neighbourhood & & & $-0.01(0.01)$ \\
\hline Number of indoor restaurants in the neighbourhood & & & $0.01(0.00)^{*}$ \\
\hline Number of fixed outdoor food stalls in the neighbourhood & & & $-0.01(0.00)^{*}$ \\
\hline Urbanicity index (ref=low) & & & $0.19(0.04)^{*}$ \\
\hline \multicolumn{4}{|l|}{ Random effects } \\
\hline Intercept & $8.33(0.23)^{*}$ & $7.88(0.23)^{\star}$ & $7.76(0.22)^{\star}$ \\
\hline Year & $0.51(0.03)^{*}$ & $0.51(0.03)^{\star}$ & $0.51(0.03)^{\star}$ \\
\hline Residual & $1.82(0.04)^{\star}$ & $1.83(0.04)^{\star}$ & $1.83(0.04)^{*}$ \\
\hline \multicolumn{4}{|l|}{ Model fit } \\
\hline$-2 L L$ & 54345.2 & 54060.4 & 54017.5 \\
\hline AIC & 54357.2 & 54090.4 & 54055.5 \\
\hline $\mathrm{BIC}$ & 54395.8 & 54187.0 & 54177.8 \\
\hline
\end{tabular}

${ }^{*} \mathrm{p}<0.05$

AIC, Akaike's information criterion; BIC, Bayesian information criterion.

Table 4 Estimates from the three-level linear growth models examining body mass index among rural women ( $\mathrm{N}=12561)$ 2004-2011

\begin{tabular}{|c|c|c|c|}
\hline & Model 1 & Model 2 & Model 3 \\
\hline Intercept & $22.92(0.05)^{\star}$ & $22.72(0.09)^{*}$ & $22.64(0.10)^{\star}$ \\
\hline Year (ref=2004) & $0.20(0.02)^{\star}$ & $0.12(0.02)^{*}$ & $0.12(0.02)^{*}$ \\
\hline \multicolumn{4}{|l|}{ Individual level } \\
\hline Age (grand-mean centred) & & $0.04(0.00)^{*}$ & $0.04(0.00)^{*}$ \\
\hline Currently married $(\mathrm{ref}=\mathrm{no})$ & & $0.65(0.08)^{*}$ & $0.66(0.08)^{*}$ \\
\hline Education level (ref=no/primary/junior) & & $-0.47(0.08)^{*}$ & $-0.49(0.08)^{\star}$ \\
\hline Per capita household income (ref=low) & & $0.04(0.02)$ & $0.04(0.02)$ \\
\hline Drinking $(r e f=n o)$ & & $-0.00(0.06)$ & $-0.00(0.06)$ \\
\hline Smoking $(r e f=n o)$ & & $-0.04(0.13)$ & $-0.04(0.13)$ \\
\hline Moderate/heavy physical activity (ref=no) & & $-0.11(0.04)^{*}$ & $-0.10(0.04)^{*}$ \\
\hline Motorcycle ownership $(\mathrm{ref}=\mathrm{no})$ & & $-0.00(0.04)$ & $-0.00(0.04)$ \\
\hline Car ownership (ref=no) & & $0.01(0.06)$ & $0.01(0.06)$ \\
\hline \multicolumn{4}{|l|}{ Neighbourhood level } \\
\hline Number of fast-food restaurants in the neighbourhood & & & $-0.02(0.01)^{\star}$ \\
\hline Number of indoor restaurants in the neighbourhood & & & $0.005(0.002)^{\star}$ \\
\hline Number of fixed outdoor food stalls in the neighbourhood & & & $-0.004(0.002)^{\star}$ \\
\hline Urbanicity index (ref=low) & & & $0.09(0.04)^{\star}$ \\
\hline \multicolumn{4}{|l|}{ Random effects } \\
\hline Intercept & $10.16(0.27)^{\star}$ & $9.37(0.25)^{*}$ & $9.32(0.25)^{\star}$ \\
\hline Year & $0.41(0.02)^{*}$ & $0.41(0.02)^{*}$ & $0.41(0.02)^{*}$ \\
\hline Residual & $1.73(0.04)^{*}$ & $1.74(0.04)^{*}$ & $1.74(0.04)^{\star}$ \\
\hline \multicolumn{4}{|l|}{ Model fit } \\
\hline$-2 \mathrm{LL}$ & 57535.1 & 57098.1 & 57077.6 \\
\hline $\mathrm{AIC}$ & 57547.1 & 57128.1 & 57115.6 \\
\hline $\mathrm{BIC}$ & 57586.0 & 57225.2 & 57238.6 \\
\hline
\end{tabular}

${ }^{*} \mathrm{p}<0.05$.

AIC, Akaike's information criterion; BIC, Bayesian information criterion. 
of protein/fat-rich food in urban and rural areas were due to the lower price of protein/fat-rich foods, compared with rice. ${ }^{25}$

While the prevalence of obesity is increasingly problematic in rural China, it is still unclear whether environmental risk factors contributed or not. Previous studies were heavily focused on individual predictors, such as lifestyles, physical activity, dietary patterns, etc. ${ }^{27}{ }^{28}$ However, currently, more studies are being conducted to assess the potential environmental factors that may contribute to the eating behaviours and health status. ${ }^{29-31}$ Low barriers to access higher energy density foods and low food prices may have contributed to higher energy and fat intake, which resulted in an obesity epidemic. Urbanisation in China influences the lifestyle of local residents, which eventually may impact on their diet. Many of them gradually change their traditional Chinese diets, which are rich in legumes, vegetables and coarse grains, into western diet, including the rural communities. ${ }^{6}$

The present study indicated a rapid increase of household income in rural China. However, the demographic description demonstrated that rural adults were still characterised by low educational level and high participation of moderate/heavy physical activity. Rural communities had been significantly exposed to urbanisation. However, our study identified that the quantity of restaurants was not related to time-varied changes. There were large gaps in the rural development that may have contributed to the phenomenon. However, the results of this study only demonstrated the trends of the rural restaurant environment as a whole, which therefore may have underestimated the regional disparities. To control the regional socioeconomic confounding effects, we included urbanicity index in the final model. Traditional indoor restaurants and fixed outdoor food stalls were the most dominant type of restaurants in rural communities, while western-type fast-food restaurants accounted only for a small proportion.

The study identified that time had a positive association with rural men and women in all models. As for individual-level variables, adults who were currently married had higher BMI values than unmarried individuals, while those who participated in moderate/heavy physical activity had lower BMI than adults with no/low physical activity. The level of education had opposite effects on BMI for men and women, with a positive association in men and a negative association in women, which is consistent with previous research. ${ }^{32}$ In addition, higher income, drinking and owning a motorcycle were associated with higher BMI, ${ }^{33}$ while smoking was associated with lower BMI, which was only significant among men. On the other hand, age was a primarily significant predictor among women, such that older rural women had a higher BMI than younger women. Car ownership was not a statistically significant predictor for BMI in rural areas.

When we added neighbourhood-level variables into the model, we found that a larger number of indoor restaurants resulted in the increase of BMI, while a larger number of fixed outdoor restaurants resulted in the decrease of BMI in rural men and women. Negative association was found between the number of fast-food restaurants in the neighbourhood and BMI in rural women. Urbanicity index was positively associated with BMI in rural adults, with a stronger association being found among men. Factors that may contribute to this finding include eating locations and food sources, which may influence the daily energy intake. ${ }^{34}$ Previous studies indicated that eating-away-from-home foods had higher total fat and lower vitamin $\mathrm{A}$, iron, fibre and calcium than eating at home foods. However, there were also inconsistent results on weight status among different types of restaurant. ${ }^{19} 35$ The density of fast-food restaurants was associated with higher BMI, while the high density of full-service restaurants was associated with lower weight status. Our findings showed inconsistent evidence with the previous studies on neighbourhood restaurants and weight status among Chinese rural adults.

In most of rural China, men were the head of families and the major source of household income, with a higher educational level and employment rate, as well as more social activities and eating out behaviours than women. Frequent fast-food consumption was reported to be related to high energy diet and low density of essential micronutrients, which may contribute to the weight gain in developed countries. ${ }^{36}$ However, fast-food consumption was not popular in China, especially in rural areas because of its relatively high price and low access. ${ }^{37}$ It was also reported that young women with higher income levels have a significant influence on western-style fast-food consumption. ${ }^{38}$ Women seem to adopt western dietary patterns easily, while men prefer to eat in more traditional ways. Low consumption of fast food may explain our results that found no association between neighbourhood fast-food restaurants and BMI in Chinese rural men. As for women who consume fast food in rural areas, most of them had a higher socioeconomic status, which meant that they had more knowledge and intention to battle with weight gain.

Indoor restaurants in China are typically full-service restaurants serving varied dishes and alcoholic drinks. They also play a major role in social activities. When eating out, people tend to eat larger portion sizes, have more energy-dense foods and increase their alcohol intake, and reduce their vegetable and fruit consumption, compared with eating at home. ${ }^{12}{ }^{13}$ A positive association between neighbourhood indoor restaurant density and BMI was found among rural adults, indicating high energy intake at indoor restaurants. On the other hand, fixed outdoor food stalls mainly provide simple Chinese dishes, such as pancakes, dumplings and noodles. Foods served at fixed outdoor food stalls were characterised by convenience, cheap price, limited choice and low nutrient value. Our results showed that the density of neighbourhood fixed outdoor food stalls 
was negatively associated with BMI. In the past decades, there was a dramatic increase of rural-to-urban migration flow in China. More rural labour force have been attracted into non-agricultural employments. ${ }^{39}$ The intense workload and limited eating environment has changed the eating behaviour of non-agricultural rural workers to find convenient, cheap and easy foods as their meals, which are mostly found at fixed outdoor food stalls.

Adults in rural areas quickly follow the weight status of their counterparts in urbanareas. One study argued that urbanisation increases the probability of having poor health, which is reflected in high fat consumption. ${ }^{40}$ Owing to low prices and abundant food supply, even the poor can afford to buy high fat content and animal source foods. Another study reported that extra income is associated with an increase of high-fat diets, particularly among the poor. ${ }^{5}$

The potentially adverse effects of urbanisation increase partly because of the easy access to cheaper processed, high-fat, added-sugar and bigger-portion foods. It is also important to note that the relative price changes matter most. If prices of fatty foods and animalsource foods decrease relative to fresh vegetables, fruits and legumes, the latter foods become less attractive, especially for poor populations. ${ }^{5} 26$

Finally, the results showed that only a small association was found between density of neighbourhood restaurants and BMI, and therefore it cannot be concluded as causality. Several potential factors that may have contributed, for instance work intensity, home location and frequency of eating out, were not included in this study. There are multiple factors that may influence the prevalence of obesity, and thus more studies should be conducted in the future.

\section{CONCLUSIONS}

Our results showed that the density of neighbourhood restaurants was significantly related to the BMI of Chinese rural adults. These results raised concerns of rural health status. Overweight and poor diets become a greater burden for the poor than the rich in China. Urbanisation and neighbourhood density of indoor restaurants were positive predictors of BMI increase among rural adults in China. Unlike the results found in most developed countries, the number of fast-food restaurants in the communities was related to the BMI decrease among rural women and no association was found among men. The fixed outdoor food stall, a common type of restaurant in China, especially in rural areas, was negatively associated with BMI. Rapid urbanisation coupled with increasing income has changed the lifestyle in rural China; however, their knowledge on health and nutrition was still limited in most rural areas. Future research is needed to understand the influence of the neighbourhood restaurant environment on the individual dietary intake and eating behaviours.
Acknowledgements The authors are grateful to all field staff of the local CDC and participants in the China Health and Nutrition Survey (CHNS) from 1989 to 2011. They also thank Dr Jiguo Zhang, Ms Ji Zhang and Ms Hongru Jiang for their advice on this paper, and Ms Levina Chandra Khoe for her language editing help.

Contributors BZ conceived and supervised the study. WD and CS completed the analyses. WD led the writing and prepared the manuscript for publication. HW, ZW and YW assisted with the study design and part of the data analyses.

Funding This work was supported by the National Institute for Nutrition and Food Safety, Chinese Center for Disease Control and Prevention, Carolina Population Center (5 R24 HD050924), the University of North Carolina at Chapel Hill, the National Institutes of Health (NIH) (R01-HD30880, DK056350, R24 HD050924 and R01-HD38700) and the Fogarty International Center, NIH for financial support for the China Health and Nutrition Survey (CHNS) data collection and analysis files from 1989 to 2011 and future surveys. This publication was supported by a subagreement from the Johns Hopkins University Bloomberg School of Public Health with funds provided by Grant No.1U54hd070725-01 funded by the Office of the Director, NIH (OD), Eunice Kennedy Shriver National Institute of Child Health and Human Development, and Office of Behavioral and Social Sciences Research.

Competing interests None.

\section{Patient consent Obtained.}

Ethics approval This research has been approved by the Institutional Review committees of the University of North Carolina at Chapel Hill and the National Institute of Nutrition and Food Safety, Chinese Center for Disease Control and Prevention. All participants gave written informed consent for their participation in the survey.

Provenance and peer review Not commissioned; externally peer reviewed.

Data sharing statement The data used for the analysis are available from the CPC at http://www.cpc.unc.edu/projects/china.

Open Access This is an Open Access article distributed in accordance with the Creative Commons Attribution Non Commercial (CC BY-NC 3.0) license, which permits others to distribute, remix, adapt, build upon this work noncommercially, and license their derivative works on different terms, provided the original work is properly cited and the use is non-commercial. See: http:// creativecommons.org/licenses/by-nc/3.0/

\section{REFERENCES}

1. Wang $\mathrm{Y}, \mathrm{Mi} \mathrm{J}$, Shan $\mathrm{X}$, et al. Is China facing an obesity epidemic and the consequences? The trends in obesity and chronic disease in China. Int J Obesity 2006;31:177-88.

2. Kelly T, Yang W, Chen CS, et al. Global burden of obesity in 2005 and projections to 2030. Int J Obes (Lond) 2008;32:1431-7.

3. Van de Poel E, O'Donnell O, Van Doorslaer E. Urbanization and the spread of diseases of affluence in China. Econ Hum Biol 2009;7:200-16.

4. Jones-Smith JC, Popkin BM. Understanding community context and adult health changes in China: development of an urbanicity scale. Soc Sci Med 2010;71:1436-46.

5. Du S, Mroz TA, Zhai F, et al. Rapid income growth adversely affects diet quality in China-particularly for the poor! Soc Sci Med 2004;59:1505-15

6. Popkin BM, Du S. Dynamics of the nutrition transition toward the animal foods sector in China and its implications: a worried perspective. J Nutr 2003;133(11 Suppl 2):3898S-906S.

7. Dong X, Hu B. Regional difference in food consumption away from home of urban residents: a panel data analysis. Agriculture Agric Sci Procedia 2010;1:271-7.

8. Orfanos P, Naska A, Trichopoulou A, et al. Eating out of home: energy, macro- and micronutrient intakes in 10 European countries. The European Prospective Investigation into Cancer and Nutrition. Eur J Clin Nutr 2009;63:S239-62.

9. Larson N, Neumark-Sztainer D, Laska MN, et al. Young adults and eating away from home: associations with dietary intake patterns and weight status differ by choice of restaurant. J Am Diet Assoc 2011;111:1696-703.

10. Lachat $\mathrm{C}$, Nago $\mathrm{E}$, Verstraeten $\mathrm{R}$, et al. Eating out of home and its association with dietary intake: a systematic review of the evidence. Obes Rev 2012;13:329-46. 
11. Guthrie JF, Lin BH, Frazao E. Role of food prepared away from home in the American diet, 1977-78 versus 1994-96: changes and consequences. J Nutr Educ Behav 2002;34:140-50.

12. O'Dwyer NA, Gibney MJ, Burke SJ, et al. The influence of eating location on nutrient intakes in Irish adults: implications for developing food-based dietary quidelines. Public Health Nutr 2007:8:258-65.

13. Vandevijvere $\mathrm{S}$, Lachat $\mathrm{C}$, Kolsteren $\mathrm{P}$, et al. Eating out of home in Belgium: current situation and policy implications. Br J Nutr 2009;102:921.

14. Kral TV, Roe LS, Rolls BJ. Combined effects of energy density and portion size on energy intake in women. Am J Clin Nutr 2004;79:962-8.

15. McCrory MA, Fuss PJ, Hays NP, et al. Overeating in America: association between restaurant food consumption and body fatness in healthy adult men and women ages 19 to 80 . Obes Res 1999;7:564-71.

16. Tin SPP, Ho SY, Mak KH, et al. Location of breakfast consumption predicts body mass index change in young Hong Kong children. Int $J$ Obes 2012;36:925-30.

17. Piernas C, Popkin BM. Food portion patterns and trends among U.S. children and the relationship to total eating occasion size, 1977-2006. J Nutr 2011;141:1159-64.

18. Kant AK, Graubard BI. Eating out in America, 1987-2000: trends and nutritional correlates. Prev Med 2004:38:243-9.

19. Duffey KJ, Gordon-Larsen P, Jacobs DR Jr, et al. Differential associations of fast food and restaurant food consumption with 3-y change in body mass index: the Coronary Artery Risk Development in Young Adults Study. Am J Clin Nutr 2007;85:201-8.

20. Casey AA, Elliott M, Glanz K, et al. Impact of the food environment and physical activity environment on behaviors and weight status in rural U.S. communities. Prev Med 2008;47:600-4.

21. Li F, Harmer P, Cardinal BJ, et al. Built environment and 1-year change in weight and waist circumference in middle-aged and older adults: Portland Neighborhood Environment and Health Study. Am J Epidemiol 2009;169:401-8.

22. Mehta NK, Chang VW. Weight status and restaurant availability: a multilevel analysis. Am J Prev Med 2008:34:127-33.

23. Du T, Sun X, Yin P, et al. Increasing trends in central obesity among Chinese adults with normal body mass index, 1993-2009. BMC Public Health 2013;13:327.

24. Xi B, Liang Y, He T, et al. Secular trends in the prevalence of general and abdominal obesity among Chinese adults, 1993-2009. Obesity Rev 2012;13:287-96.

25. Liu H, Fang $\mathrm{H}$, Zhao Z. Urban-rural disparities of child health and nutritional status in China from 1989 to 2006. Econ Hum Biol 2013;11:294-309.
26. Popkin BM, Adair LS, Ng SW. Global nutrition transition and the pandemic of obesity in developing countries. Nutr Rev 2012;70:3-21.

27. Ahn S, Zhao H, Tai-Seale M, et al. The longitudinal effects of behavioral, health, and socio-demographic factors on body mass index among older Chinese adults. Int J Public Health 2012;57:269-77.

28. Shankar B. Socio-economic drivers of overnutrition in China. J Hum Nutr Diet 2010;23:471-9.

29. Block JP, Christakis NA, O'Malley AJ, et al. Proximity to food establishments and body mass index in the Framingham Heart Study offspring cohort over 30 years. Am J Epidemiol 2011;174:1108-14.

30. Bodor JN, Rice JC, Farley TA, et al. The association between obesity and urban food environments. $J$ Urban Health 2010;87:771-81.

31. Duffey KJ, Gordon-Larsen P, Jacobs DR, et al. Differential associations of fast food and restaurant food consumption with 3-y change in body mass index: the Coronary Artery Risk Development in Young Adults Study. Am J Clin Nutr 2007:85:201-8.

32. Jones-Smith JC, Gordon-Larsen P, Siddiqi A, et al. Emerging disparities in overweight by educational attainment in Chinese adults (1989-2006). Int J Obes (Lond) 2012;36:866-75.

33. Qin L, Stolk RP, Corpeleijn E. Motorized transportation, social status, and adiposity: the China Health and Nutrition Survey. $A m J$ Prev Med 2012;43:1-10.

34. Poti JM, Popkin BM. Trends in energy intake among US children by eating location and food source, 1977-2006. J Am Diet Assoc 2011;111:1156-64.

35. Inagami S, Cohen DA, Brown AF, et al. Body mass index, neighborhood fast food and restaurant concentration, and car ownership. J Urban Health 2009;86:683-95.

36. Bowman SA, Vinyard BT. Fast food consumption of U.S. adults: impact on energy and nutrient intakes and overweight status. J Am Coll Nutr 2004;23:163-8.

37. Adair LS, Popkin BM. Are child eating patterns being transformed globally? Obes Res 2005;13:1281-99.

38. Curtis KR, McCluskey JJ, Wahl TI. Consumer preferences for western-style convenience foods in china. China Econ Rev 2007;18:1-14.

39. Tuan F, Somwaru A, Diao X. Rural labor migration, characteristics, and employment patterns. International Food Policy Research Institute (IFPRI), 2000.

40. Van de Poel E, O'donnell O, Van Doorslaer E. Is there a health penalty of China's rapid urbanization? Health Econ 2012;21:367-85. 